\section{Additional pedigree supporting the frequent origin of XXYY from consecutive meiotic non-disjunction in paternal gametogenesis}

SUMMARY A 48,XXYY Sardinian patient, born to a 46,XX mother heterozygous for the $G d$ Mediterranean mutant, and to a $46, X Y$ father hemizygous for the same mutant, was found to have a mosaic distribution of G6PD $(+)$ and G6PD $(-)$ peripheral red blood cells. The most likely interpretation of this finding is that the propositus is an additional example of an XXYY zygote derived from a consecutive meiotic non-disjunction during paternal gametogenesis.

In the course of a population study on Klinefelter's syndrome in the island of Sardinia, where the incidence of G6PD deficiency of Mediterranean type may be as high as $30 \%$ among males (Siniscalco et al., 1966), we found an XXYY male born to a G6PD-deficient father and to a mother who is an obligatory heterozygote for the $G d$ Mediterranean mutant.

\section{Clinical and laboratory findings}

The patient, 22 years old, had the following findings:
(1) Bilateral atrophy of the testes (average size 8 in arbitrary units; normal values $11.86 \pm$ $0 \cdot 15)$.

(2) Slender (height $176 \mathrm{~cm}$, weight $73 \mathrm{~kg}$; normal values $158.65 \mathrm{~cm} \pm 0.47$ and $61.9 \mathrm{~kg} \pm 0.52)$.

(3) High titres of FSH and $\mathrm{LH}(66.6 \mathrm{mIU} / \mathrm{ml}$ and $50 \mathrm{mIU} / \mathrm{ml}$, respectively; normal values $7.05 \mathrm{mIU} / \mathrm{ml} \pm 0.85$ and $5.06 \mathrm{mIU} / \mathrm{ml} \pm$ $1 \cdot 09)$.

(4) $40 \%$ of buccal mucosa cells were sex chromatin positive.

(5) Of 50 metaphases from peripheral blood cultures, 48 had 48 chromosomes. Ten of these metaphases were karyotyped with quinacrine banding and found to be $48, X X Y Y$. The presence of the extra $X$ and of the extra $Y$ chromosomes was confirmed by microscopical screening also in all the other metaphases which were not karyotyped. Cytogenetical studies were performed on both parents of the propositus and found to be normal.

The patient has normal sexual development, no gynaecomastia, and no apparent impairment of mental capacity and behaviour. He completed obligatory schooling with average performances and is at present working as a farmer. $\mathrm{He}$ is the seventh of nine children, born after a normal pregnancy, when his mother was 36 years old and his father 39. The mother had had 3 earlier spontaneous abortions. There is no consanguinity and no medical problems in the family.

I

II

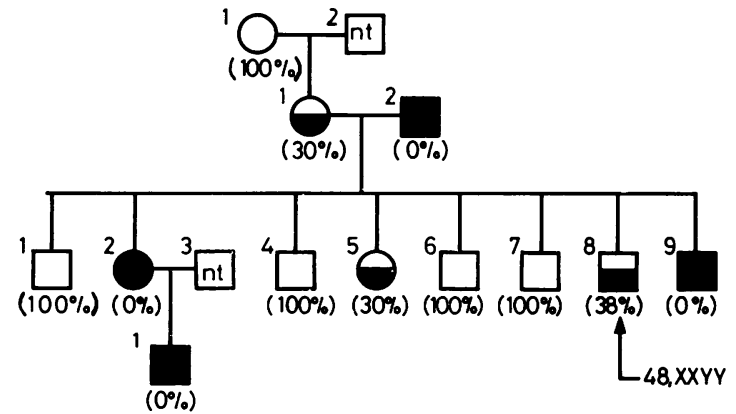

IV

$(0 \%)$

Hemizygote and homozygote for the $G d^{B}$ normal allele

Hemizygote and homozygote for the Gd ${ }^{\text {mediterranean mutant }}$

Heterozygote $\mathrm{Gd}^{\mathrm{B}} / \mathrm{Gd}$ mediterranean

Klinefelter patient heterozygote $G d^{B} / G d^{\text {mediter ranean }}$

not tested

L Propositus

( ) \%G6PD positive red blood cells after the methaemoglobin elution test

Fig. Family pedigree. 


\section{Discussion}

The propositus and his mother have a mosaic population of $\mathrm{G} 6 \mathrm{PD}(+)$ and $\mathrm{G} 6 \mathrm{PD}(-)$ peripheral red blood cells, which is characteristic of heterozygotes with the genotype $G d B / G d$ Mediterranean (Rinaldi et al., 1976). This conclusion is supported by the analysis of the red cell G6PD phenotypes of all members of the pedigree (Fig.), on the basis of which the presence of other G6PD alleles, besides the ones mentioned above, can be excluded. In view of these findings, the possibility that the XXYY genome of the propositus is the result of an early mitotic non-disjunction of a normal XY zygote can also be excluded, since in this case he should have been homozygous for the mutant or the normal allele. Thus, discarding the unlikely event of an independent occurrence of non-disjunction in both parents of prereductional type in the mother and postreductional in the father, the most likely explanation remains that both types of meiotic non-disjunction have occurred consecutively during the paternal gametogenesis. The $\mathrm{X}$ and the $\mathrm{Y}$ must have gone into the same 'spermatocyte II' during the reductional meiosis, and both Ys, but only one $\mathrm{X}$ (and the Gd Mediterranean mutant carried by it), must have segregated during the equational division in the 'spermatid' which matured into the sperm that fertilised a normal haploid egg carrying the $G d B$ allele.

To the best of our knowledge, this is the third instance, among a total of $36 \mathrm{XXYY}$ propositi ascertained so far (De la Chapelle et al., 1964; Pfeiffer et al., 1966; Sanger et al., 1977), in which the origin of the supernumerary sex chromosomes can be identified as the result of consecutive nondisjunction having occurred during paternal gametogenesis.
This study is part of a genetical survey supportedकुy the Italian National Research Council and by NeI grant CA-17085 from the National Science Foundation. The authors are grateful to Professor Siniscalco for his advice and support.

ANTONiETtina Rinaldi, ${ }^{1,2}$ Nicole

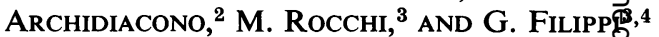
${ }^{1}$ Centro di Genetica Evoluzionistica del CN太R, Università di Roma, Rome, Italy; ${ }^{2}$ Sloan-Kettering Institute for Cancer Research, New York, USA;

${ }^{3}$ Istituto di Genetica Medica, Universitōodi Trieste, Trieste, Italy; $\overline{\text { abd } d}$ ${ }^{4}$ Istituto per l'Infanzia di Trieste, Trieste, Ifäly

\section{References}

De la Chapelle, A., Hortling, H., Sanger, R., and Race, RN (1964). Successive non-disjunction at first and second meiotic division of spermatogenesis: evidence of chromosomes and Xg. Cytogenetics, 3, 334-341.

$\overrightarrow{\mathrm{CR}}$.

Pfeiffer, R. A., Körver, G., Sanger, R., and Race, R.CR.

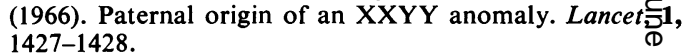

Rinaldi, A., Filippi, G., and Siniscalco, M. (1976). Variabitity of red cell phenotypes between and within individuals in an unbiased sample of 77 heterozygotes for G6PD deficiency in Sardinia. American Journal of Human Genetics, 28, 496-505.

Sanger, R., Tippett, P., Gavin, J., Teesdale, P., and Daniêds, G. L. (1977). Xg groups and sex chromosome abnormaliक्wes in people of northern European ancestry: an addendun. Journal of Medical Genetics, 14, 210-211.

Siniscalco, M., Filippi, G., Latte, B., Piomelli, S., Rattažzi, M., Gavin, J., Sanger, R., and Race, R. R. (1966). Failöre to detect linkage between $\mathrm{Xg}$ and other X-borne locBin Sardinians. Annals of Human Genetics, 29, 231-252.

Requests for reprints to Professor M. Siniscalco, Section 6108, Sloan-Kettering Institute for Cancer Research, 425 East 68th Street, New York, NYY 10021, USA. 